\section{The First Genomic Resources for Phymatotrichopsis omnivora, a Soilborne Pezizomycete Pathogen with a Broad Host Range} Chakradhar Mattupalli, ${ }^{1,2}$ Jason B. Shiller, ${ }^{1}$ Prasanna Kankanala, ${ }^{1}$ Nick Krom, ${ }^{1}$ Stephen M. Marek, ${ }^{3}$
Kirankumar S. Mysore, ${ }^{1}$ and Carolyn A. Young ${ }^{1, \dagger}$

${ }^{1}$ Noble Research Institute, LLC, 2510 Sam Noble Parkway, Ardmore, OK, 73401

${ }^{2}$ San Luis Valley Research Center, Colorado State University, 0249 East Road 9 North, Center, CO 81125

${ }^{3}$ Department of Entomology and Plant Pathology, Oklahoma State University, Stillwater, OK, 74078

\begin{abstract}
Phymatotrichopsis omnivora is a destructive plant pathogen causing root rot disease of alfalfa, cotton, pecan, grape, and many other important dicotyledonous species. A member of the family Rhizinaceae, in the class Pezizomycetes, $P$. omnivora is a soilborne ascomycete fungus that is difficult to maintain in culture, currently genetically intractable, and for which there are no publicly available genomic resources. We have generated draft genome sequences of four $P$. omnivora isolates obtained from cotton and alfalfa, growing in Texas and Oklahoma. These genome sequences will provide new insights into the biology of the fungus, including the factors responsible for its broad host range and pathogenicity.
\end{abstract}

\section{Genome Announcement}

The ascomycete fungus Phymatotrichopsis omnivora belongs to the family Rhizinaceae (Marek et al. 2009) and represents one of the few known plant pathogens from the order Pezizales, which is notably comprised of saprobes (e.g., Ascobolus immersus) and symbionts (e.g., Tuber melanosporum). P. omnivora is a destructive plant pathogen causing root rot disease (commonly referred as cotton root rot or Phymatotrichum root rot) of many plants including alfalfa, cotton, pecan, grape, and vegetable crops. This fungus has an extraordinarily broad host range and has been shown to exhibit high plasticity, infecting as a necrotrophic or hemibiotrophic pathogen (Kankanala et al. 2020; Taubenhaus and Ezekiel 1936). Of the 2,116 plant species tested, $81 \%$ were susceptible to the pathogen, but notably, all monocotyledonous plants were not affected (Taubenhaus and Ezekiel 1936). P. omnivora has no known sexual stage, and the pathogen is endemic to southwestern United States and Mexico, where the disease is visibly active during summer (Percy 1983; Young et al. 2015). Despite its economic importance, there are no public genomic resources available for $P$. omnivora. Several attempts to transform this fungus have been made, but to date, this fungus remains genetically intractable (Uppalapati et al. 2010). Furthermore, this fungus is difficult to maintain in the lab as active cultures readily lose pathogenicity. To better understand this recalcitrant pathogen both from a biological and a management perspective, genomes of four isolates of $P$. omnivora were sequenced and assembled. To capture knowledge of pathogen diversity, we selected $P$. omnivora isolates that originated from two different host crops and three locations, and represented two different mating types (Table 1). One of the selected isolates, NFPo1 was used to study P. omnivora-host and -nonhost interactions with Medicago truncatula (susceptible), Arabidopsis thaliana (partially resistant), and Brachypodium distachyon (resistant/nonhost) (Kankanala et al. 2020).

${ }^{\dagger}$ Corresponding author: C. A. Young; cayoung.kiwi@gmail.com

*The $e$-Xtra logo stands for "electronic extra" and indicates there are supplementary materials published online.

The author(s) declare no conflict of interest.

Accepted for publication 9 March 2021.

$e-$ tra* $^{*}$

Funding

This work was supported by funds from the Noble Research Institute, LLC.

\section{Keywords}

alfalfa, ascomycete, cotton root rot, Phymatotrichum root rot 
Table 1. Genome assembly features of Phymatotrichopsis omnivora isolates

\begin{tabular}{|c|c|c|c|c|}
\hline Isolate & NFPo $1^{a}$ & NFPo18 ${ }^{a}$ & NFPo20 ${ }^{a}$ & NFPo30 \\
\hline Host & Alfalfa & Alfalfa & Alfalfa & Cotton \\
\hline Isolation year & 2014 & 2014 & 2014 & 2007 \\
\hline Location (county, state) & Carter, Oklahoma & Love, Oklahoma & Love, Oklahoma & Reeves, Texas \\
\hline $\begin{array}{l}\text { Genome assembly size } \\
\quad(\mathrm{Mb})\end{array}$ & 109.0 & 107.1 & 108.7 & 107.8 \\
\hline Number of contigs & 22,063 & 25,419 & 25,171 & 26,805 \\
\hline Repeat regions & $38 \%$ & $39 \%$ & $39 \%$ & $40 \%$ \\
\hline GC content (\%) & $43 \%$ & $44 \%$ & $43 \%$ & $44 \%$ \\
\hline $\begin{array}{l}\text { Number of predicted } \\
\text { genes }\end{array}$ & 14,827 & 14,728 & 15,033 & 14,747 \\
\hline $\begin{array}{l}\text { BUSCO completeness } \\
\text { (fungal lineage) }(\%)\end{array}$ & 94 & 94 & 93 & 93 \\
\hline
\end{tabular}

${ }^{a}$ Isolate NFPo1 is described in Kankanala et al. (2020), NFPo18 and NFPo20 originated from the study site described in Mattupalli et al. (2015, 2018, 2019).

b Mating-type genes were identified using TBLASTN with the mating-type genes from Tuber melanosporum (MAT1-1-1 accession number HM370280) and Tuber indicum (MAT1-2-1 accession number KF318364) as query sequences. The accession numbers of the $P$. omnivora mating-type sequences are MW357816 to MW357819.

Four hyphal-tipped pure cultures of $P$. omnivora isolated from alfalfa and cotton in Texas and Oklahoma (NFPo1, 18, 20, and 30; Table 1) were grown from mycelial plugs in liquid modified ATCC medium 1078 (Marek et al. 2009) in the dark without shaking at $28^{\circ} \mathrm{C}$ for 8 to 10 days. Genomic DNA was extracted using the Quick-DNA Fungal/Bacterial DNA MiniPrep kit (Zymo Research Corporation, Invine, CA). Sequencing libraries were prepared using Nextera XT DNA library kit and each $P$. omnivora isolate was sequenced on its own flow cell using the v3 paired end 600 cycle kit (600 bp paired end reads) on the Illumina MiSeq platform (San Diego, CA) at the University of Kentucky HealthCare Genomics Center (Lexington, KY). De novo genome assembly was performed using SPAdes (Bankevich et al. 2012), and repetitive DNA sequences were identified with RepeatScout version 2.1.4 (Price et al. 2005). The genomes were masked using RepeatMasker version 4.0.9 (Smit et al. 2015) before gene prediction was performed using AUGUSTUS v3.3.2 with the incorporation of RNA-seq (150 bp paired end reads) data from NFPo1 in vitro growth on modified ATCC medium 1078 and half-strength Murashige-Skoog medium supplemented with vitamins (PhytoTechnology Laboratories, Shawnee Mission, KS) for 7 days at $28^{\circ} \mathrm{C}$. Genome completeness was evaluated using BUSCO (Simão et al. 2015), and a phylogeny of selected Pezizomycetes species (Fig. 1) was generated using 100 BUSCO genes (Supplementary Table S1). Amino acid sequences of each gene were aligned separately using MAFFT (Nakamura et al. 2018), and then a super alignment was created by concatenating all individual alignments. The phylogeny was estimated from this alignment using RAxML version 8.2.12 (Stamatakis 2014) with the GAMMAWAG. The phylogenetic relationships observed in the multigene phylogeny (Fig. 1) are consistent with trees based on large subunit and small subunit rDNA sequences and the deduced amino acid sequences of RPB2 (Marek et al. 2009). SignalP version 4.1 (Petersen et al. 2011) and dbCAN2 (Zhang et al. 2018) were used to identify predicted secreted proteins or carbohydrate-active enzymes (CAZymes), respectively.

The draft genome assemblies of the isolates were larger than most fungal genomes and rich in repeats. Assembly length ranged from 107.1 to $109.0 \mathrm{Mb}$ with repeats accounting for 38 to $40 \%$ of the sequences (Table 1). Given the repetitiveness of the genomes and because they were assembled without long reads, it is likely that the genomes are larger than these estimates. The number of predicted genes was $\sim 15,000$. Despite the fragmented genomes, a high proportion of the gene-coding regions were captured in these assemblies given that BUSCO scores ranged between 93 and $94 \%$.

These genomes will be a useful resource for those studying $P$. omnivora and cotton root rot disease. It will now be possible to generate genetic tools to study population structure and develop sensitive in-field detection methods for growers and stakeholders whose land might be a reservoir for this pathogen. Although a sexual stage has never been reported for this fungus, the sequenced isolates possessed different mating types, with NFPo20 and NFPo30 containing the MAT1-1 idiomorph, whereas NFPo1 and NFPo18 contained MAT1-2. This may indicate the potential for $P$. omnivora to be heterothallic and able to sexually recombine in nature. 


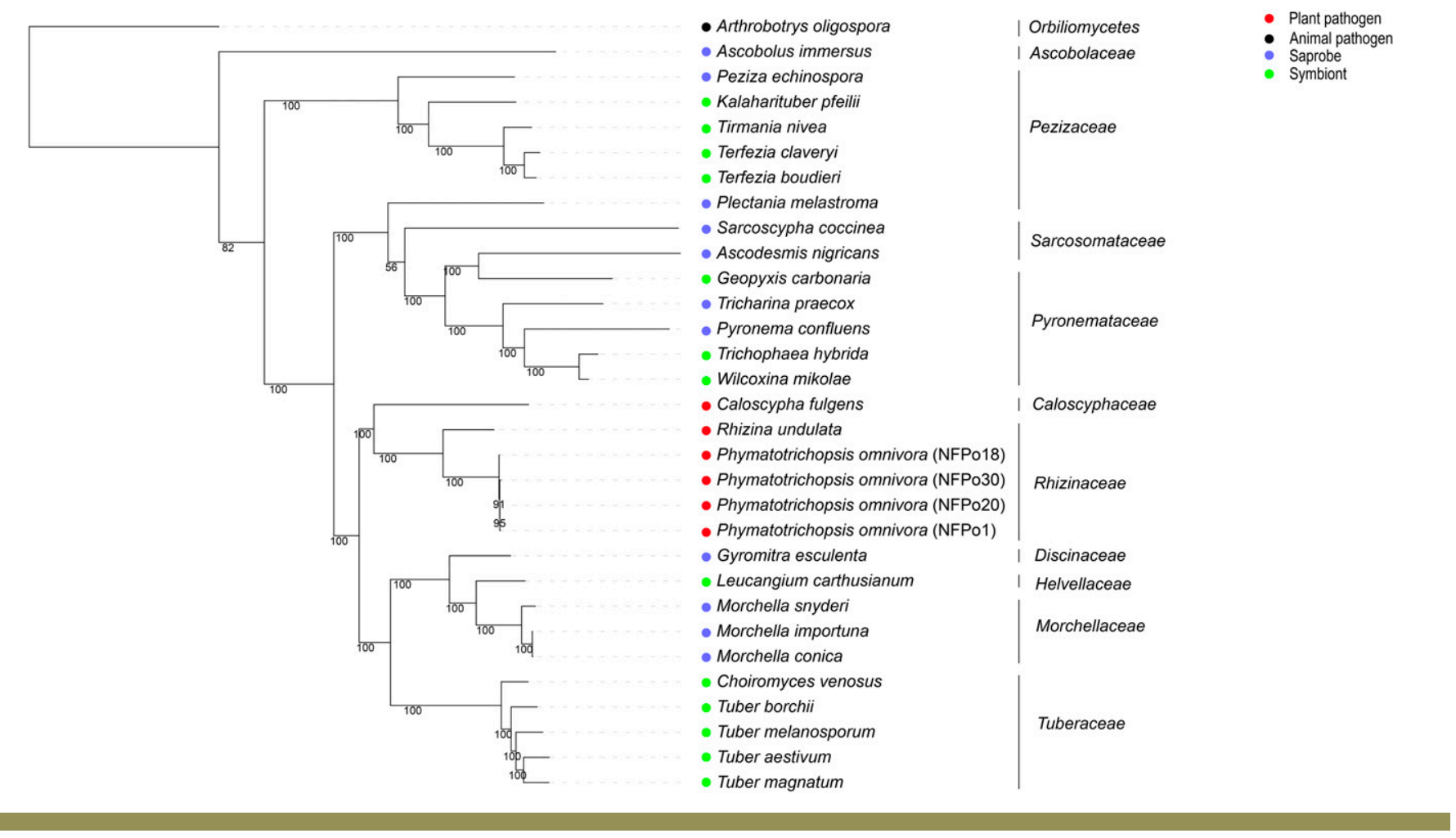

Fig. 1. Phylogeny of Phymatotrichopsis omnivora isolates sequenced in this study with selected representatives of Pezizomycetes and Orbiliomycetes (outgroup). The phylogeny was estimated on a super alignment of 100 concatenated BUSCO gene alignments (genes listed in Supplementary Table S1). Species included in the phylogeny have been annotated by lifestyle as either, plant pathogen (red), animal pathogen (black), saprobe (blue), or symbiont (green).

Beyond the use to the immediate $P$. omnivora research community, these genomes will enable useful genomic comparisons within the class Pezizomycetes. This class is of interest due to its inclusion of the choice edible taxa, ectomycorrhizal truffles (Tuberaceae and Terfeziaceae) and saprotrophic morels (Morchellaceae), and the few plant-pathogenic species in the Rhizinaceae clade, where P. omnivora groups with Rhizina undulata and Caloscypha fulgens (Fig. 1). Currently, many genomic resources are available for this class (https://mycocosm.jgi.doe.gov/pezizomycetes/pezizomycetes. info.html) and have been used to investigate the biology of the ectomycorrhizal truffle lifestyle (Marqués-Gálvez et al. 2021; Martin et al. 2010; Murat et al. 2018). Likewise, the addition of these genomes from $P$. omnivora will be useful for future comparative genomics projects investigating how the root-pathogenic lifestyle evolved in the Pezizomycetes.

The genome sequences have been deposited into GenBank under BioProject PRJNA641071 with BioSamples SAMN15340118 to SAMN15340121, and sequence read archive accessions SRR13120354 to SRR13120357. The RNAseq data are found under BioProject PRJNA642231 with BioSamples SAMN15390343 to SAMN1539035. The accession numbers of the mating-type gene sequences are MW357816 to MW357819.

\section{Literature Cited}

Bankevich, A., Nurk, S., Antipov, D., Gurevich, A. A., Dvorkin, M., Kulikov, A. S., Lesin, V. M., Nikolenko, S. I., Pham, S., and Prjibelski, A. D. 2012. SPAdes: A new genome assembly algorithm and its applications to single-cell sequencing. J. Comput. Biol. 19:455-477.

Kankanala, P., Jones, P., Nandety, R. S., Jacobson, D. A., and Mysore, K. S. 2020. Plasticity of Phymatotrichopsis omnivora infection strategies is dependent on host and nonhost plant responses. Plant Cell Environ. 43:1084-1101.

Marek, S., Hansen, K., Romanish, M., and Thorn, R. 2009. Molecular systematics of the cotton root rot pathogen, Phymatotrichopsis omnivora. Persoonia 22:63-74.

Marqués-Gálvez, J. E., Miyauchi, S., Paolocci, F., Navarro-Ródenas, A., Arenas, F., Pérez-Gilabert, M., Morin, E., Auer, L., Barry, K. W., Kuo, A., Grigoriev, I. V., Martin, F. M., Kohler, A., and Morte, A. 2021. Desert truffle genomes reveal their reproductive modes and new insights into plant-fungal interaction and ectendomycorrhizal lifestyle. New Phytol. 229:2917-2932.

Martin, F., Kohler, A., Murat, C., Balestrini, R., Coutinho, P. M., Jaillon, O., Montanini, B., Morin, E., Noel, B., Percudani, R., Porcel, B., Rubini, A., Amicucci, A., Amselem, J., Anthouard, V., Arcioni, S., Artiguenave, F., Aury, J.-M., Ballario, P., Bolchi, A., Brenna, A., Brun, A., Buée, M., Cantarel, B., Chevalier, G., Couloux, A., Da Silva, C., Denoeud, F., Duplessis, S., Ghignone, S., Hilselberger, B., lotti, M., Marçais, B., Mello, A., Miranda, M., Pacioni, G., Quesneville, H., Riccioni, C., Ruotolo, R., Splivallo, R., Stocchi, V., Tisserant, E., Viscomi, A. R., Zambonelli, A., Zampieri, E., Henrissat, B., Lebrun, M.-H., Paolocci, F., Bonfante, P., Ottonello, S., and Wincker, P. 2010. Périgord black truffle genome uncovers evolutionary origins and mechanisms of symbiosis. Nature 464:1033-1038. 
Mattupalli, C., Komp, M. R., and Young, C. A. 2015. Integrating geospatial technologies and unmanned aircraft systems into the grower's disease management toolbox. APS Features.

Mattupalli, C., Moffet, C. A., Shah, K. N., and Young, C. A. 2018. Supervised classification of RGB aerial imagery to evaluate the impact of a root rot disease. Remote Sens. 10:917.

Mattupalli, C., Seethepalli, A., York, L. M., and Young, C. A. 2019. Digital imaging to evaluate root system architectural changes associated with soil biotic factors. Phytobiomes J. 3:102-111.

Murat, C., Payen, T., Noel, B., Kuo, A., Morin, E., Chen, J., Kohler, A., Krizsán, K., Balestrini, R., Da Silva, C., Montanini, B., Hainaut, M., Levati, E., Barry, K. W., Belfiori, B., Cichocki, N., Clum, A., Dockter, R. B., Fauchery, L., Guy, J., lotti, M., Le Tacon, F., Lindquist, E. A., Lipzen, A., Malagnac, F., Mello, A., Molinier, V., Miyauchi, S., Poulain, J., Riccioni, C., Rubini, A., Sitrit, Y., Splivallo, R., Traeger, S., Wang, M., Žifčáková, L., Wipf, D., Zambonelli, A., Paolocci, F., Nowrousian, M., Ottonello, S., Baldrian, P., Spatafora, J. W., Henrissat, B., Nagy, L. G., Aury, J.-M., Wincker, P., Grigoriev, I. V., Bonfante, P., and Martin, F. M. 2018. Pezizomycetes genomes reveal the molecular basis of ectomycorrhizal truffle lifestyle. Nat. Ecol. Evol. 2:1956-1965

Nakamura, T., Yamada, K. D., Tomii, K., and Katoh, K. 2018. Parallelization of MAFFT for large-scale multiple sequence alignments. Bioinformatics 34:24902492.

Percy, R. 1983. Potential range of Phymatotrichum omnivorum as determined by edaphic factors. Plant Dis. 67:981-983.
Petersen, T. N., Brunak, S., Von Heijne, G., and Nielsen, H. 2011. SignalP 4.0: Discriminating signal peptides from transmembrane regions. Nat. Methods 8:785-786.

Price, A. L., Jones, N. C., and Pevzner, P. A. 2005. De novo identification of repeat families in large genomes. Bioinformatics 21:i351-i358.

Simão, F. A., Waterhouse, R. M., Ioannidis, P., Kriventseva, E. V., and Zdobnov, E. M. 2015. BUSCO: Assessing genome assembly and annotation completeness with single-copy orthologs. Bioinformatics 31:3210-3212.

Smit, A., Hubley, R., and Green, P. 2015. RepeatMasker Open-4.0. https://www. repeatmasker.org/

Stamatakis, A. 2014. RAxML version 8: A tool for phylogenetic analysis and postanalysis of large phylogenies. Bioinformatics 30:1312-1313.

Taubenhaus, J. J., and Ezekiel, W. N. 1936. A rating of plants with reference to their relative resistance or susceptibility to Phymatotrichum root rot. Tex. Agric. Exp. Stn. Bull. 527:1-52.

Uppalapati, S. R., Young, C. A., Marek, S. M., and Mysore, K. S. 2010. Phymatotrichum (cotton) root rot caused by Phymatotrichopsis omnivora: Retrospects and prospects. Mol. Plant Pathol. 11:325-334.

Young, C. A., Uppalapati, S. R., Mysore, K. S., and Marek, S. 2015. Phymatotrichosis root rot. Pages 44-46 in: Compendium of Alfalfa Diseases and Pests. D. A. Samac, L. H. Rhodes, and W. O. Lamp, eds. American Phytopathological Society, St. Paul, $\mathrm{MN}$.

Zhang, H., Yohe, T., Huang, L., Entwistle, S., Wu, P., Yang, Z., Busk, P. K., Xu, Y., and Yin, Y. 2018. dbCAN2: A meta server for automated carbohydrate-active enzyme annotation. Nucleic Acids Res. 46:W95-W101. 